Introduction: The G protein-coupled oestrogen receptor 1 (GPER-1) is a potential prognostic marker in breast cancer. However, its role in male breast cancer $(M B C)$ is still unknown. This study evaluates the expression of GPER-1 in MBC samples and correlates these data with clinical and pathological parameters including patients' survival.

Material and methods: For this retrospective analysis of a prospectively maintained cohort of patients with MBC, we examined 161 specimens for GPER-1 expression using immunohistochemistry. An immunoreactive score (IRS) was calculated based on staining intensity and the percentage of positive tumour cells. Then, we correlated GPER-1 IRS with clinical and pathological parameters, and overall and relapse-free survival.

Results: About $40 \%$ of MBC samples were positive for GPER-1 expression $(I R S \geq 4)$. There was no significant correlation with clinicopathological parameters, such as hormone receptor status or grading. However, a statistical trend was observed for tumour size ( $\geq 2 \mathrm{~cm}, p=0.093$ ). Kaplan-Meier survival analysis revealed no significant correlation with relapse-free survival. However, there was a significant correlation with overall survival, but when we adjusted the log-rank $p$-value to compensate for the cut-off point optimization method, it rose above 0.1 . Additionally, GPER-1-positive patients were older at diagnosis. When adjusted for age by multivariable Cox regression analysis, the significance of GPER-1 status for survival was further reduced.

Conclusions: We found no significant prognostic value of GPER-1 in this MBC cohort as anticipated from studies on female BC. Future studies with higher sample size are needed to further verify a potential sex-specific role of GPER-1.

Key words: male breast cancer, $M B C$ survival analysis, GPER-1, GPR30, OS, RFS.

Contemp Oncol (Pozn) 2021; 25 (3): 204-212 DOI: https://doi.org/10.5114/wo.2021.110010

\section{The impact of G protein-coupled oestrogen receptor 1 on male breast cancer: a retrospective analysis}

\author{
Jan-Hendrik Maiwald ${ }^{1}$, Susanne Sprung ${ }^{2}$, Piotr Czapiewski ${ }^{1,3}$, Wiebke Lessel ${ }^{1}$, \\ Anna Scherping ${ }^{1}$, Dirk Schomburg ${ }^{4}$, Markus Plaumann ${ }^{4}$, Bartłomiej Tomasik ${ }^{5,6}$, \\ Gerhard Behre $^{7}$, Johannes Haybaeck ${ }^{1,2,8,9}$, Atanas Ignatov ${ }^{10}$, Holm Eggemann ${ }^{11}$, \\ Norbert Nass ${ }^{1,7}$
}

1Department of Pathology, Otto von Guericke University Magdeburg, Magdeburg, Germany

Institute of Pathology, Neuropathology and Molecular Pathology, Medical University of Innsbruck, Innsbruck, Austria

${ }^{3}$ Department of Pathology, Dessau Medical Centre, Dessau, Germany

${ }^{4}$ Institute for Biometrics and Medical Informatics, Otto von Guericke University Magdeburg, Magdeburg, Germany

Department of Biostatistics and Translational Medicine, Medical University of Lodz, Lodz, Poland

${ }^{6}$ Department of Radiation Oncology, Dana-Farber Cancer Institute, Boston, MA, USA

${ }^{7}$ Clinic for Internal Medicine I, Dessau Medical Centre, Dessau, Germany

${ }^{8}$ Diagnostic \& Research Centre for Molecular Biomedicine, Institute of Pathology,

Medical University of Graz, Graz, Austria

${ }^{9}$ Center for Biomarker Research in Medicine, Graz, Austria

${ }^{10}$ Department of Obstetrics and Gynaecology, Otto von Guericke University Magdeburg, Magdeburg, Germany

${ }^{11}$ Department of Obstetrics and Gynaecology, Hospital Magdeburg GmbH, Magdeburg, Germany

\section{Introduction}

Male breast cancer (MBC) is a rare disease that accounts for less than 1\% of male cancer cases in the United States and 1.1\% of cases in Germany [1-3]. The exact aetiology of this disease is still largely unknown; described risk factors include age, BRCA1 and 2 mutations, obesity, Klinefelter's syndrome, and radiation exposure [4].

More than $90 \%$ of $M B C$ cases are oestrogen receptor (ER)-positive, and 80-90\% progesterone receptor (PR)-positive. Compared to female breast cancer (FBC), these frequencies are higher [5-7]. HER-2/neu is expressed in $5-29 \%$ of MBC cases compared to $15-25 \%$ in FBC cases [8-10]. The most common histologic type of $\mathrm{MBC}$ is the invasive carcinoma of no special type [10]. Compared to women, breast cancers of lobular histology are less frequently encountered, which is most probably due to the significantly lower number of lobules in male breast tissue [5]. Due to its rarity, the biology of $M B C$ is still not fully understood, and cell culture model systems are still in development.

The G protein-coupled oestrogen receptor 1 (GPER-1) was first identified in 1997 [11]. Regarding transcription modulation and rapid nongenomic action, GPER-1, together with classical oestrogen receptors (ERs), appears to mediate the action of oestrogen [12, 13]. In hormone-sensitive tumours, such as breast and ovarian cancer, GPER-1 is involved in proliferative oestrogen signalling $[14,15]$. The role of GPER-1 as a potential tumour suppressor is a subject of debate. In cell culture studies, activation of GPER-1 by the specific agonist G-1 resulted in reduced cell proliferation and cell death in ER-positive as well as ER-negative cell lines [16-18]. However, in FBC patients, the situation seems more complicated because GPER-1-positive cases exhibited a shorter relapse-free survival [14], but this depended on anti-oestrogen 
treatment in ER-positive cases. In ER-positive BC, the agonistic influence of tamoxifen on GPER-1 seems to favour the development of acquired tamoxifen-resistance $[13,15,19]$ The question of whether a blockade of the GPER-1 signalling pathway could overcome tamoxifen resistance, thus being a target in the therapy of oestrogen-related tumours, still needs to be answered $[12,20]$.

To date, the literature contains no data on the expression of GPER-1 in MBC or its potential impact on patients' survival. In this study, we investigated the expression of GPER-1 in 161 patients with primary MBC and correlated these data with clinical and pathological parameters comprising patients' survival.

\section{Material and methods}

\section{Patients}

We investigated MBC cases included in the German prospective cancer registry of MBC. This trial was registered at the German Clinical Trials Register DRKS under the number DRKS00009536. Male patients, diagnosed with histologically confirmed primary breast cancer, and older than 18 years were included in the study. This cancer registry contains data on the age at diagnosis, patient and tumour characteristics, operative, neo-, and/or adjuvant treatment, date and localization of relapse, date and cause of death, secondary cancer, and comorbidities. The database was compiled between 2009 and 2018. The last update was in May 2020. Other studies conducted on the basis of this database have already been published [7, 21, 22] Formalin-fixed, paraffin-embedded tumour samples from 161 patients were available for this retrospective analysis.

\section{Materials}

Immunostaining was performed on 3- $\mu$ m slices [14] using a Benchmark XT automatic staining system (Ventana, Unterhaching, Germany) in batches of about 30 slides. As positive control, an FBC sample with known histochemistry score was included into each batch. The staining procedure was essentially as described in [14].

The stained slides were evaluated by pathologists of the Department of Pathology, Magdeburg, Germany, and the Medical University of Innsbruck, Austria using light microscopy (SS, PC). Staining intensity and staining extensity were scored as previously described [19]. Staining intensity was scored as follows: 0 (no staining), 1 (weak), 2 (moderate), and 3 (strong response). Staining extensity was scored numerically as 1 ( $<10 \%$ positive cells), 2 (10-50\%positive cells), or 3 (> 50\% positive cells). Both scores were multiplied for each sample, thus forming the immunoreactive score (IRS) [14]. Therefore, this score included values from 0 to 9 .

\section{Statistics}

Statistical calculations were performed using IBM SPSS Statistics Version 26.0 for Microsoft Windows (Armonk, NY, USA) or IBM SPSS Statistics Subscription for Apple Mac-OS (IBM SPSS, Armonk, NY, USA). Computer scripts were programmed in the language $\mathrm{R}$ (https://www.R-project.org).
Overall survival (OS) was defined as the period between the date of diagnosis and date of death from any cause. Relapse-free survival (RFS) was defined as the time span between the date of diagnosis and the date of loco-regional and/or distant relapse. Loco-regional relapse included the recurrence in ipsilateral breast, chest wall, or regional lymph nodes. Distant recurrences consisted of distant lymph node metastases (beyond the ipsilateral axillary, infra- and/ or supraclavicular, internal mammary area), as well as of metastases in bone (including bone marrow), brain, liver, lung (including pleura and lymphangitic carcinomatosis), and other organs (including peritoneum, other organs not elsewhere classified, and skin tumours not affecting the breast and chest wall). The paired Wilcoxon signed rank test was used to compare GPER-IRS of tumour tissue compared to adjacent non-tumorous tissue. For correlation of ordinal variables, Spearman's rank correlation test was used. The impact of the GPER-1 status on OS and RFS was analysed using the Kaplan-Meier method, and significance was determined using the log-rank test. In the case of OS, this $p$-value was further corrected using a permutation test to consider the fact that the cut-off point was determined by the minimal-p-value-approach [23]. Furthermore, uni- and multivariable Cox regression analysis was applied. The GPER-1 expression was correlated to clinical and pathological parameters by cross-tabulation test using a twosided Fisher's exact test for determining significant differences. Generally, $p<0.05$ was considered as an indicator of a significant deviation from the null hypothesis, and $p<0.1$ was considered as a statistical trend.

\section{Results}

The $G$ protein-coupled ER 1 immunoreactivity analysis was performed on specimens from 161 patients. Figure 1 shows representative examples of GPER-1 staining. Comparing adjacent, non-tumourous tissue with tumour, the paired Wilcoxon signed rank test revealed no significant differences in staining intensity $(p=0.28)$. Based on the minimal $p$-value approach using the log-rank value for OS, an IRS $\geq 4$ was considered GPER-1-positive. Sixty-five patients (40.4\%) were GPER-1 positive and 96 (59.6\%) were GPER-1 negative. This cut-off is one step higher than that established in our studies for FBC. Using this cut-off value of $\geq 3$, no significance was observed in Kaplan-Meier survival analysis (for OS: $p=0.065$, see below). The mean age at initial diagnosis was 66.1 years (range: 26-93, standard deviation: \pm 13.0 years). It was significantly lower in GPER-1-positive than in GPER-1-negative patients (63.0 vs. 68.2 years, $p=0.018$, Table 1). Therefore, we applied age-adjusted Cox regression to further evaluate this result. Further data on the cohort can be found in Table 2.

\section{The G protein-coupled oestrogen receptor 1} and clinicopathological parameters

We then tested for correlation between GPER-1 status and major clinicopathological parameters (Table 2). There was no significant difference in any of these clinical and pathological parameters, but we found a trend concerning tumour size $(p=0.093)$. Because most of the cases were ER and PR posi- 

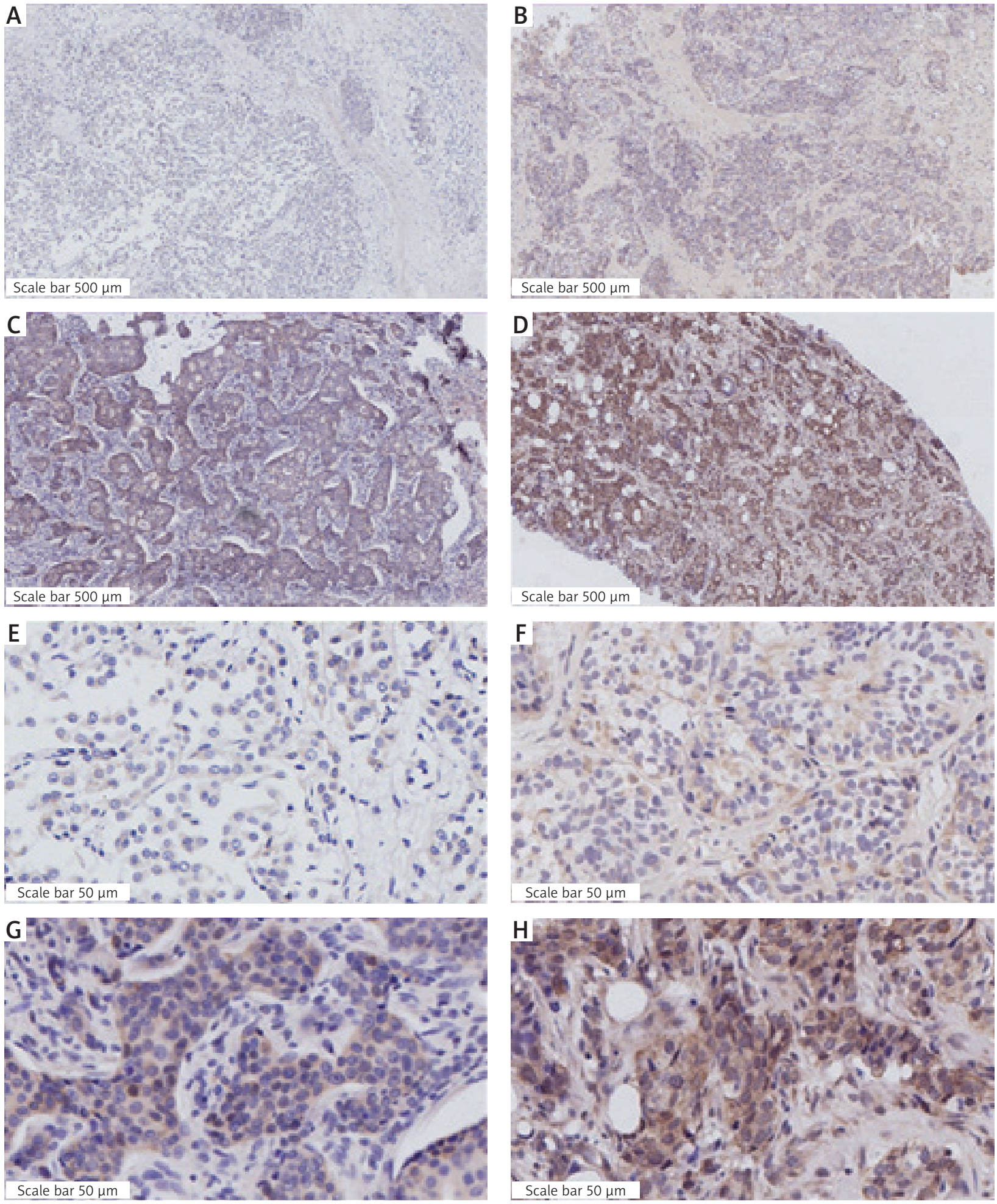

Fig. 1. Representative images of the $G$ protein-coupled oestrogen receptor-1 histochemical staining. No (A, E), weak (B, F), moderate (C, G), and strong staining intensity $(\mathrm{D}, \mathrm{H})$

tive, we also correlated the ER and PR scores with the GPER-1 score, but again, no significant result was obtained.

Survival analysis and G protein-coupled oestrogen receptor status

Data from 150 patients were available for the analysis of OS and RFS (Table 3). For relapse-free survival, 26 events were observed, whereas for overall survival, death was confirmed to be due to cancer in 5 cases, 11 deaths were attributed to other reasons, and for the remaining 11 the cause of death was not documented.

Among the clinical and pathological parameters, obesity, tumour size, lymph node status, and type of axillary lymph node surgery were associated with OS. Lymph node 
status, as well as breast and axillary lymph node surgery, had a significant influence on RFS (Tables 4 and 5).

Kaplan-Meier analysis revealed that the GPER-1 status $(\geq 4)$ was associated with better/improved overall survival, but not with RFS (Fig. 2, log-rank $p=0.029$ and $p=0.637$, respectively). However, after correction using a permutation test with 10,000 samples, the $p$-value for OS rose to 0.109 (this $p$-value was calculated using a pseudo random seed of 42).

As there was a significant difference in age at diagnosis depending on GPER-1 status (Table 1), we applied multivariable Cox regression analysis to correct the parameters effect for age (Table 6). For this purpose, age at diagnosis was used without further modification. Here, GPER-1 lost its significance for OS ( $p=0.065, \mathrm{HR}=0.44,95 \% \mathrm{Cl}$ : 0.18-1.11). Age at diagnosis itself was also a significant factor for OS ( $p=0.043, \mathrm{HR}=1.034,95 \% \mathrm{Cl}: 1.001-1.068$ ). However, in multivariable analysis together with GPER-1 this significance decreased ( $p=0.075, \mathrm{HR}=1.029,95 \% \mathrm{Cl}$ : 0.996-1.06). In a multivariable Cox regression with algorithmic variable selection including GPER-1-status, age, tumour size, and $\mathrm{N}$, only the lymph-node status remained a significant factor for RFS ( $p=0.001, \mathrm{HR}=5.733,95 \% \mathrm{Cl}$ : 2.208-14.884) and OS ( $p=0.002, \mathrm{HR}=4,73,95 \% \mathrm{Cl}: 1.796-$ 12.477). There was also no significant interaction between tamoxifen therapy and GPER-1 status (data not shown).

\section{Discussion}

This is the first study investigating GPER-1 in primary MBC cases. A total of 161 patients were studied, and an IRS value $\geq 4$ was defined as a positive result. This cut-off point was based on Kaplan-Meier survival analysis logrank $p$-value optimization. We then correlated OS and RFS, as well as clinical and pathological parameters, with this GPER-1 status.

GPER-1 status was positive in $40.4 \%$ of cases. In previous studies, the rate of GPER-1 positivity ranged from 56 to $80 \%$ in $\mathrm{FBC}[14,19,24]$ using a lower cut-off value $(I R S \geq 3)$ although the same staining protocol was applied. Using this cut-off value ( $\geq 3), 50.3 \%$ of MBC cases would be GPER-1 positive in our study. These results possibly indicate that expression of GPER is weaker in men, which would justify the higher cut-off value. Nevertheless, this requires further analysis. Another explanation for this might lie in technical differences such as different lots of the antibody, different fixation methods of the study centres, or storage conditions of the samples.

Also applying a cut-off value of IRS $\geq 3$, the median age remained significantly higher in the GPER-1-negative cases ( $p=0.027$, difference: 4.8 years). Significant correlations to other clinicopathologic parameters were not detected. Nevertheless, significant differences in OS are lost with this cut-off ( $p=0.061$ Kaplan-Meier analysis, log-rank $p$ ). Therefore, splitting the collective at IRS $\geq 4$ seemed most reasonable.

At first glance, GPER-1 expression was significantly related to favourable OS. This confirms the assumption of a prognostically favourable effect of GPER-1 in studies of women with ER-positive BC $[19,25]$. GPER-1 has also
Table 1. Characterization of patients

$\begin{array}{lcccc}\begin{array}{l}\text { Age at initial } \\ \text { diagnosis [years] }\end{array} & \text { All } & \begin{array}{c}\text { GPER-1 } \\ \text { positive }\end{array} & \begin{array}{c}\text { GPER-1 } \\ \text { negative }\end{array} & p \text {-value } \\ \text { Mean } \pm \text { SD } & 66.1 \pm 13.0 & 63.0 \pm 14.1 & 68.2 \pm 11.9 & 0.018 \\ \text { Range } & 26-93 & 26-86 & 37-93 & \\ \text { Total } & 144 & 59 & 85 & \\ \text { Missing } & 17 & 6 & 11 & \\ \text { Age at death } & & & & \\ \text { [years] } & & & & \\ \text { Mean } \pm \text { SD } & & 67.4 \pm 14.0 & 71.8 \pm 12.2 & 0.047 \\ \text { Age at relapse } & & & & \\ \text { [years] } & & & & \\ \text { Mean } \pm \text { SD } & & 67.3 \pm 14.1 & 71.6 \pm 12.4 & 0.055\end{array}$

GPER-1 - G protein-coupled oestrogen receptor-1

Age at initial diagnosis, at death, and at relapse and body mass index stratified for $G$ protein-coupled oestrogen receptor 1 status $(\geq 4)$ in male breast cancer patients. Fisher's exact t-test $p$ is given

been described as a favourable prognostic factor in earlystage cervical carcinoma, as well as in-vitro in ovarian cancer and in granulosa cell tumours [26-28]. Nevertheless, we did not find any association between GPER-1 status and the likelihood of relapse, but it should be taken into account that the statistical power of our study is lower than in most studies for FBC. Such an association of GPER-1 with metastasis has been described previously [29]. However, that study used a different system for the IRS evaluation. Nevertheless, another study on FBC [14] found a stronger effect of GPER-IRS on RFS than on OS. While the observation period was comparable for both groups (Table 4), we found a significant difference in both age at initial diagnosis and age at death (Table 1) depending on GPER-1 status. Previous studies examining women found no significant difference in age at initial diagnosis [19, 30]. This is a newly found association and possibly a distinct characteristic of MBC. However, this complicates the interpretation of the survival analysis. In our study, the cause of death is ill-defined. Additionally, the multivariable Cox regression analysis demonstrated a reduction of significance for GPER-1 status to a trend, when adjusted to age. This drop in significance also applies for age itself; thus, both factors contribute to OS. The effect of GPER-IRS on OS is uncertain, especially when we consider that the optimization of the cut-off value is known to cause an overestimation of significance in survival analysis [23, 31]. Indeed, when we corrected the log-rank $p$-value for this effect by permutation testing [32], significance was lost $(p=0.109)$. Altogether, as there was no significant correlation with RFS and an uncertainty of the cause of death in this study, we cannot conclusively show an effect of GPER-status on survival of our MBC patients. Based on these assumptions, GPER-1 might play a different role in MBC than in FBC.

We also found no association between tamoxifen therapy and GPER-1 status and its effect on RFS and OS. Men displayed a significantly prolonged OS for tamoxifen-treatment when compared with aromatase inhibitors (Als), which was also shown in a larger sample of patients from this registry study $[22,33]$. Presumably due to the small number of patients not given tamoxifen $(n=20)$ and pa- 
Table 2. Clinical and pathological characteristics and Fisher test $p$-values for $G$ protein-coupled oestrogen receptor-1 positive $(\geq 4)$ vs. G protein-coupled oestrogen receptor 1 positive negative male breast cancer specimens (and ordinal by ordinal correlation)

\begin{tabular}{|c|c|c|c|c|c|c|c|}
\hline \multirow[t]{2}{*}{ Characteristics } & \multicolumn{2}{|c|}{ All } & \multicolumn{2}{|c|}{ GPER-1 positive } & \multicolumn{2}{|c|}{ GPER-1 negative } & \multirow[t]{2}{*}{$p$-value } \\
\hline & $n$ & $\%$ & $n$ & $\%$ & $n$ & $\%$ & \\
\hline Total & 161 & 100 & 65 & 40.4 & 96 & 59.6 & \\
\hline Deceased & & & & & & & 0.112 \\
\hline Yes & 27 & 18.0 & 6 & 9.8 & 21 & 23.6 & \\
\hline No & 123 & 82.0 & 55 & 90.2 & 68 & 76.4 & \\
\hline Relapse & & & & & & & 0.821 \\
\hline Yes & 26 & 17.3 & 10 & 16.4 & 16 & 18.0 & \\
\hline No & 124 & 82.7 & 51 & 83.6 & 73 & 82.0 & \\
\hline BMI $\left[\mathrm{kg} / \mathrm{m}^{2}\right]$ & & & & & & & $0.618^{8}$ \\
\hline Normal (18.5-24.9) & 32 & 21.2 & 11 & 7.3 & 21 & 13.9 & \\
\hline Overweight (25-29.9) & 73 & 48.3 & 30 & 19.9 & 43 & 28.5 & \\
\hline Obesity ( $\geq 30)$ & 46 & 30.5 & 19 & 12.6 & 27 & 17.9 & \\
\hline ER & & & & & & & 1.000 \\
\hline Positive & 157 & 98.1 & 64 & 98.5 & 93 & 97.9 & \\
\hline Negative & 3 & 1.9 & 1 & 1.5 & 2 & 2.1 & \\
\hline PR & & & & & & & 1.000 \\
\hline Positive & 153 & 95.0 & 62 & 95.4 & 91 & 94.8 & \\
\hline Negative & 8 & 5.0 & 3 & 4.6 & 5 & 5.2 & \\
\hline HER-2/neu & & & & & & & 0.486 \\
\hline Positive & 21 & 13.1 & 10 & 15.4 & 11 & 11.6 & \\
\hline Negative & 139 & 86.9 & 55 & 84.6 & 84 & 88.4 & \\
\hline Triple-negative & & & & & & & 0.784 \\
\hline$\overline{\text { Yes }}$ & 15 & 9.4 & 7 & 10.8 & 8 & 8.5 & \\
\hline$\overline{\text { No }}$ & 144 & 90.6 & 58 & 89.2 & 86 & 91.5 & \\
\hline Histopathology & & & & & & & 0.833 \\
\hline Invasive carcinoma NST & 133 & 82.6 & 53 & 81.5 & 80 & 83.3 & \\
\hline Others & 28 & 17.4 & 12 & 18.5 & 16 & 16.7 & \\
\hline Tumour size & & & & & & & 0.093 \\
\hline$<2 \mathrm{~cm}$ & 74 & 50.0 & 35 & 59.3 & 39 & 43.8 & \\
\hline$\geq 2 \mathrm{~cm}$ & 74 & 50.0 & 24 & 40.7 & 50 & 56.2 & \\
\hline Lymph node status & & & & & & & 0.823 \\
\hline pNo, pN1 & 116 & 82.3 & 46 & 80.7 & 70 & 83.3 & \\
\hline $\mathrm{pN2}, \mathrm{pN} 3$ & 25 & 17.7 & 11 & 19.3 & 14 & 16.7 & \\
\hline $\mathrm{G}$ & & & & & & & $0.715^{\&}$ \\
\hline G1 & 15 & 10.1 & 4 & 2.7 & 11 & 7.4 & \\
\hline $\mathrm{G} 2$ & 88 & 59.0 & 36 & 24.2 & 52 & 34.9 & \\
\hline G3 & 46 & 30.9 & 19 & 12.8 & 27 & 18.1 & \\
\hline Operations & & & & & & & 0.543 \\
\hline Ablatio mammae & 136 & 91.9 & 53 & 89.8 & 83 & 93.3 & \\
\hline Others & 12 & 8.1 & 6 & 10.2 & 6 & 6.7 & \\
\hline \multicolumn{8}{|l|}{ Axilla } \\
\hline Dissection $(y / n)$ & 41 & 31.8 & 14 & 28.6 & 27 & 33.8 & $0.566^{5}$ \\
\hline SNB (y/n) & 70 & 54.3 & 26 & 53.1 & 44 & 55.0 & $0.857^{\S}$ \\
\hline Dissection + SNB (y/n) & 17 & 13.2 & 9 & 18.4 & 8 & 10.0 & $0.189^{5}$ \\
\hline Radiotherapy & & & & & & & 0.091 \\
\hline Yes & 73 & 50.7 & 34 & 59.6 & 39 & 44.8 & \\
\hline No & 71 & 49.3 & 23 & 40.4 & 48 & 55.2 & \\
\hline
\end{tabular}

GPER-1 - G protein-coupled oestrogen receptor-1, BMI - body mass index, ER - oestrogen receptor, PR - progesterone receptor, SNB - sentinel node biopsy,

$\$$ - p-value was calculated vs. all other cases 
tients with unknown endocrine therapy $(n=17)$, we could not demonstrate any effect. Also, a significant number of patients stopped using tamoxifen early. As a result, the administration time was often short. Tamoxifen resistance has been reported to occur especially in long-term use [20]. It is possible that the observed length of time the drug was administered in our study was too short for resistance to develop. However, GPER-1 may not be a factor determining tamoxifen resistance in men. Although a positive GPER-1 status was not associated with an improved probability of recurrence, the possibility of a therapy specifically tailored for GPER-1 status should be considered further. Prospective studies should evaluate whether this could have a significant impact on relapse-free time.

Investigations of MBC have revealed that compared to women, ER and PR are expressed more frequently - in approximately $95 \%$ and $80 \%$ of cases, respectively $[5,6]$. Although our study supports this result, the observed positive ER and PR status of $98.1 \%$ and $95.0 \%$, respectively, is higher than in some previous studies. These results are largely consistent with data from recent publications (ER: 96-97\% PR: 91-92\%) [34, 35]. A correlation between GPER-1
Table 3. Observation period stratified for G protein-coupled oestrogen receptor-1 status $(\geq 4)$

\begin{tabular}{|lcccc}
$\begin{array}{l}\text { Observation } \\
\text { period [weeks] }\end{array}$ & All & $\begin{array}{c}\text { GPER-1 } \\
\text { positive }\end{array}$ & $\begin{array}{c}\text { GPER-1 } \\
\text { negative }\end{array}$ & $p$-value \\
Median & 208.9 & 215.6 & 206.3 & \\
Mean \pm SD & $197.5 \pm 72.0$ & $204.8 \pm 69.6$ & $192.4 \pm 73.5$ & 0.555 \\
Range & $15-319$ & $36-300$ & $15-319$ & \\
Total & 150 & 61 & 89 & \\
Missing & 11 & 4 & 7 &
\end{tabular}

GPER-1 - G protein-coupled oestrogen receptor-1

$P$-value was determined using the t-test

and ER or PR status was shown in female patients [19]. Our study does not confirm this observation, even when we correlated the respective scores to compensate for the low frequency of ER cases.

As in women [19], HER-2/neu expression did not correlate with GPER-1 status. Nevertheless, Sjöström et al. reported opposite results [36]; however, GPER-1 status was evaluated differently and only low-risk FBC patients were included, resulting in only $13.1 \%$ positive HER-2/neu cases.

Table 4. Kaplan-Meier analysis of overall survival

\begin{tabular}{|c|c|c|c|c|c|}
\hline \multirow[t]{2}{*}{ Characteristics } & \multicolumn{4}{|c|}{ Overall survival [weeks] } & \multirow{2}{*}{$\begin{array}{c}\text { 5-year survival } \\
\text { rate [\%] }\end{array}$} \\
\hline & Mean & SD & $95 \% \mathrm{Cl}$ & $p$-value & \\
\hline GPER-1 & & & & $0.029^{\S}$ & \\
\hline Positive $(\geq 4)$ & 281.6 & 7.3 & $267.3-295.9$ & & 86.6 \\
\hline Negative $(<4)$ & 265.7 & 10.1 & $246.0-285.5$ & & 72.0 \\
\hline $\mathrm{BMI}\left[\mathrm{kg} / \mathrm{m}^{2}\right]$ & & & & 0.045 & \\
\hline Obese $(\mathrm{BMI} \geq 30)$ & 254.1 & 11.4 & $231.7-276.5$ & & 64.3 \\
\hline Non-obese $(\mathrm{BMI}<30)$ & 286.2 & 8.2 & $270.1-302.3$ & & 83.8 \\
\hline Tumour size & & & & 0.010 & \\
\hline$\leq 2 \mathrm{~cm}$ & 281.8 & 4.6 & $272.8-290.7$ & & 85.5 \\
\hline$>2 \mathrm{~cm}$ & 260.6 & 11.8 & $237.4-283.6$ & & 71.3 \\
\hline Lymph node status & & & & $<0.001$ & \\
\hline pN0, pN1 & 293.2 & 6.5 & $280.5-306.0$ & & 84.7 \\
\hline pN2, pN3 & 214.0 & 20.3 & $174.1-253.8$ & & 48.7 \\
\hline Grading & & & & 0.812 & \\
\hline G1 & 253.3 & 21.1 & 212.0-294.6 & & 64.2 \\
\hline G2 & 280.9 & 9.3 & $262.7-299.1$ & & 79.8 \\
\hline G3 & 263.9 & 11.2 & 241.9-285.8 & & 78.4 \\
\hline Operation & & & & 0.932 & \\
\hline Ablatio & 281.4 & 7.3 & $267.1-295.7$ & & 78.6 \\
\hline \multicolumn{6}{|l|}{ Axilla } \\
\hline Dissection & 248.5 & 13.1 & $222.9-274.1$ & $0.001^{\&}$ & 64.6 \\
\hline SNB & 305.3 & 6.6 & $292.3-318.3$ & $0.003^{8}$ & 91.8 \\
\hline Dissection + SNB & 275.9 & 15.9 & $244.8-307.0$ & $0.875^{\&}$ & 80.0 \\
\hline Radiotherapy & & & & 0.694 & \\
\hline Yes & 264.9 & 9.0 & $247.2-282.6$ & & 75.4 \\
\hline No & 279.2 & 10.4 & $258.8-299.5$ & & 79.2 \\
\hline
\end{tabular}

GPER-1 - G protein-coupled oestrogen receptor-1, BMI-body mass index, ${ }^{\S}-p$-value was calculated vs. all other cases Overall survival in weeks and 5-year survival rate is given. P-value was calculated using the log-rank test 
Table 5. Kaplan-Meier analysis of relapse-free survival

\begin{tabular}{|c|c|c|c|c|c|}
\hline \multirow[t]{2}{*}{ Characteristics } & \multicolumn{4}{|c|}{ Relapse-free time [weeks] } & \multirow{2}{*}{$\begin{array}{c}\text { 5-year relapse- } \\
\text { free rate [\%] }\end{array}$} \\
\hline & Mean & SD & $95 \% \mathrm{Cl}$ & $p$-value & \\
\hline GPER-1 & & & & 0.637 & \\
\hline Positive $(\geq 4)$ & 268.2 & 9.1 & 250.3-286.1 & & 77.8 \\
\hline Negative $(<4)$ & 260.8 & 9.3 & $242.6-278.9$ & & 75.8 \\
\hline $\mathrm{BMI}\left[\mathrm{kg} / \mathrm{m}^{2}\right]$ & & & & 0.157 & \\
\hline Obese (BMI $\geq 30)$ & 251.6 & 13.5 & $225.2-278.0$ & & 66.9 \\
\hline Non-obese $(\mathrm{BMI}<30)$ & 269.0 & 7.5 & $254.4-283.7$ & & 80.7 \\
\hline Tumour size & & & & 0.279 & \\
\hline$\leq 2 \mathrm{~cm}$ & 269.0 & 7.6 & $254.1-283.9$ & & 81.8 \\
\hline$>2 \mathrm{~cm}$ & 259.4 & 10.5 & $238.9-280.0$ & & 73.2 \\
\hline Lymph node status & & & & 0.001 & \\
\hline pNO, pN1 & 275.9 & 6.3 & $263.5-288.2$ & & 45.2 \\
\hline $\mathrm{pN} 2, \mathrm{pN} 3$ & 196.5 & 19.8 & $157.8-235.3$ & & 82.1 \\
\hline Grading & & & & 0.145 & \\
\hline $\mathrm{G} 1$ & 232.8 & 24.7 & $184.3-281.3$ & & 55.1 \\
\hline $\mathrm{G} 2$ & 273.1 & 8.1 & $257.2-289.0$ & & 82.9 \\
\hline $\mathrm{G} 3$ & 251.4 & 12.7 & $226.4-276.4$ & & 69.0 \\
\hline Operations & & & & 0.028 & \\
\hline Ablatio & 270.5 & 6.7 & $257.5-283.6$ & & 80.8 \\
\hline Others & 212.9 & 20.4 & $172.9-252.9$ & & 40.5 \\
\hline \multicolumn{6}{|l|}{ Axilla } \\
\hline$\underline{\text { Dissection }(y / n)}$ & 235.0 & 15.6 & $204.4-265.7$ & $0.004^{\S}$ & 58.4 \\
\hline SNB $(y / n)$ & 273.2 & 7.4 & $259.0-287.4$ & $0.028^{\S}$ & 83.2 \\
\hline Dissection + SNB (y/n) & 286.4 & 13.0 & $260.9-311.9$ & $0.233^{\S}$ & 90.9 \\
\hline Radiotherapy & & & & 0.549 & \\
\hline Yes & 259.8 & 9.5 & $240.9-278.2$ & & 71.9 \\
\hline No & 259.6 & 10.0 & $240.2-279.3$ & & 79.8 \\
\hline
\end{tabular}

GPER-1 - G protein-coupled oestrogen receptor 1, BMI-body mass index, $\S$ - p-value was calculated vs. all other cases

Relapse-free survival in weeks and 5-year survival rate is given. P-value was caluclated using the log-rank test

A review on this still controversial topic reported that the rate of HER-2/neu positivity is probably lower in men than in women because some of the older studies on HER-2/ neu status may have been biased [37]. Comparable rates

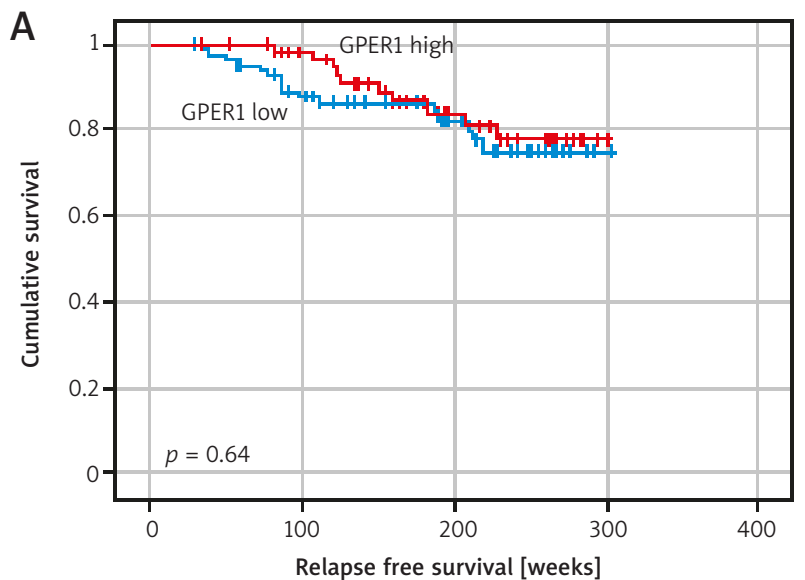

of $14 \%$ and $16 \%$ positives were reported in studies conducted in 2015 [34, 35].

We also found no significant association between GPER-1 status and tumour grading. Compared with other studies,

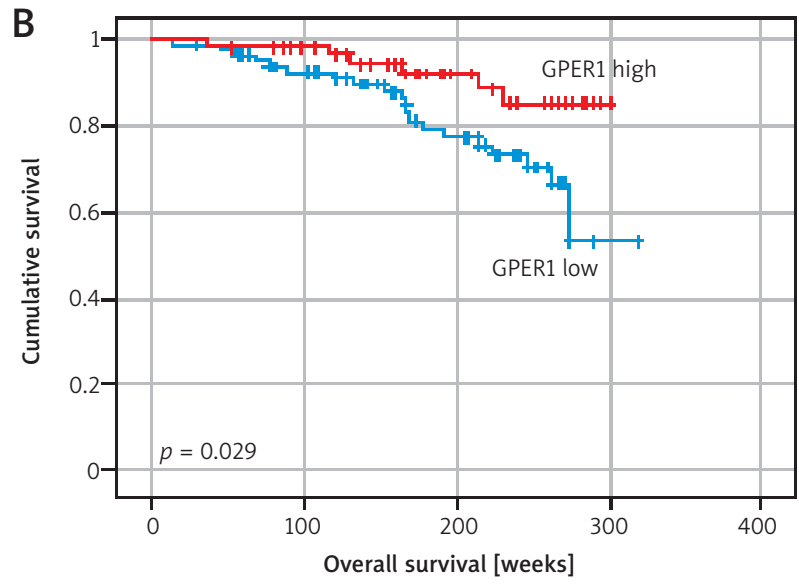

Fig. 2. Kaplan-Meier survival analysis of the $G$ protein-coupled oestrogen receptor-1 status $(\geq 4)$ for relapse-free survival and overall survival. Log-rank $p$ not corrected for age is given 
Table 6. Cox regressions analysis for survival of male breast cancer patients. All data shown were adjusted for age

\begin{tabular}{|c|c|c|c|c|c|c|}
\hline \multirow[t]{2}{*}{ Characteristics } & \multicolumn{3}{|c|}{ Overall survival } & \multicolumn{3}{|c|}{ Relapse-free survival } \\
\hline & $p$ & HR & $95 \% \mathrm{Cl}$ & $p$ & HR & $95 \% \mathrm{Cl}$ \\
\hline GPER-1 ( $\geq 4$ vs. $<4)$ & 0.082 & 0.441 & $0.175-1.111$ & 0.404 & 0.706 & $0.312-1.599$ \\
\hline Tumour size $<2.0 \mathrm{vs} . \geq 2.0 \mathrm{~cm}$ & 0.015 & 2.962 & $1.234-7.105$ & 0.216 & 1.690 & $0.736-3.880$ \\
\hline N0, N1 vs. N2, N3 & 0.001 & 4.314 & $1.780-10.455$ & 0.001 & 4.738 & $1.862-12.054$ \\
\hline ER (positive vs. negative) & 0.314 & 0.354 & $0.047-2.678$ & 0.408 & 0.430 & $0.058-3.175$ \\
\hline PR (positive vs. negative) & 0.012 & 0.168 & $0.042-0.673$ & 0.396 & 0.514 & $0.111-2.390$ \\
\hline HER-2/neu (positive vs. negative) & 0.603 & 1.330 & $0.455-3.889$ & 0.295 & 1.688 & $0.633-4.498$ \\
\hline Axillary dissection & 0.003 & 4.490 & $1.678-12.015$ & 0.002 & 3.772 & $1.596-8.914$ \\
\hline SNB & 0.009 & 0.224 & $0.073-0.684$ & 0.011 & 0.307 & $0.123-0.764$ \\
\hline
\end{tabular}

GPER-1 - G protein-coupled oestrogen receptor 1, ER-oestrogen receptor, PR-progesterone receptor, SNB - sentinel node biopsy

these findings provide room for speculation. While one study was able to find an association between GPER-status and low tumour grading, others failed to do so [19,29]. These 2 sources again considered FBC, which might allow the suggestion of the existence of another tumour entity in men.

We also did not determine the exact subcellular localization of GPER-1, which seems to be linked to other histopathological and prognostic parameters depending on its localization in the nucleus or cytoplasm [38, 39]. In particular, localization in the plasma membrane has been identified as a poor prognostic marker in one study [36].

\section{Conclusions}

In summary, this study is the first to investigate GPER-1 status in $M B C$ specimens. The results revealed a much weaker prognostic value, compared to FBC. However, GPER status correlated with age at diagnosis and was loosely associated with improved OS.

\section{Acknowledgements}

This article does not contain any studies with animals performed by any of the authors. All procedures performed in studies involving human participants were in accordance with the ethical standards of the institutional and/ or national research committee and with the 1964 Helsinki declaration and its later amendments or comparable ethical standards.

Written informed consent was obtained from all patients before recruitment. Additional individual consent for this analysis was not needed.

We are grateful for the support of the study by the Warburg-Melchior-Olearius-Stiftung. M.M. Warburg \& Co, Herr Dr. Olearius, Ferdinandstraße 75, 20095 Hamburg (http:// www.mmwarburggruppe.com/en). Bartłomiej Tomasik gratefully acknowledges the financial support provided by the Polish National Agency for Academic Exchange (the Walczak Programme).

\section{References}

1. Krebs in Deutschland 2015/2016, Robertv Koch-Institut, Berlin 2019. doi: $10.25646 / 5977$.
2. Jemal A, Murray T, Samuels A, et al. Cancer Statistics, 2003. Cancer J Clin 2003; 53: 5-26.

3. Siegel RL, Miller KD, Jemal A. Cancer statistics, 2020. Cancer J Clin 2020; 70: 7-30.

4. Ruddy KJ, Winer EP. Male breast cancer: risk factors, biology, diagnosis, treatment, and survivorship. Ann Oncol 2013; 24: 1434-1443.

5. Giordano SH. Breast cancer in men. N Engl J Med 2018; 378: 23112320.

6. Sarmiento S, McColl M, Musavi L, et al. Male breast cancer: a closer look at patient and tumor characteristics and factors that affect survival using the National Cancer Database. Breast Cancer Res Treat 2020; 180: 471-479.

7. Streng M, Ignatov A, Reinisch $M$, et al. A comparison of tumour size measurements with palpation, ultrasound and mammography in male breast cancer: first results of the prospective register study. J Cancer Res Clin Oncol 2018; 144: 381-387.

8. Johansen Taber KA, Morisy LR, Osbahr AJ, Dickinson BD. Male breast cancer: risk factors, diagnosis, and management. Oncol Rep 2010; 24: 1115-1120.

9. Rayson D, Erlichman C, Suman VJ, et al. Molecular markers in male breast carcinoma. Cancer 1998; 83: 1947-1955.

10. Korde LA, Zujewski JA, Kamin L, et al. Multidisciplinary meeting on male breast cancer: Summary and research recommendations. J Clin Oncol 2010; 28: 2114-2122.

11. Carmeci C, Thompson DA, Ring HZ, et al. Identification of a gene (GPR30) with homology to the G-protein-coupled receptor superfamily associated with estrogen receptor expression in breast cancer. Genomics 1997; 45: 607-617.

12. Wang D, Hu L, Zhang G, et al. G protein-coupled receptor 30 in tumor development. Endocrine 2010; 38: 29-37.

13. Prossnitz ER, Arterburn JB, Smith HO, et al. Estrogen signaling through the transmembrane $\mathrm{G}$ protein-coupled receptor GPR30. Ann Rev Physiol 2008; 70: 165-190.

14. Ignatov A, Ignatov T, Weissenborn C, et al. G-protein-coupled estrogen receptor GPR30 and tamoxifen resistance in breast cancer. Breast Cancer Res Treat 2011; 128: 457-466.

15. Lappano R, Pisano A, Maggiolini M. GPER function in breast cancer: an overview. Front Endocrinol 2014; 5: 66.

16. Weißenborn C, Ignatov T, Poehlmann A, et al. GPER functions as a tumor suppressor in MCF-7 and SK-BR-3 breast cancer cells. J Cancer Res Clin Oncol 2014; 140: 663-671.

17. Weißenborn C, Ignatov T, Ochel H-J, et al. GPER functions as a tumor suppressor in triple-negative breast cancer cells. J Cancer Res Clin Oncol 2014; 140: 713-723.

18. Vo D-KH, Hartig R, Weinert S, et al. G-protein-coupled estrogen receptor (GPER)-specific agonist G1 induces ER stress leading to cell death in MCF-7 cells. Biomolecules 2019; 9: 503.

19. Ignatov T, Claus M, Nass N, et al. G-protein-coupled estrogen receptor GPER-1 expression in hormone receptor-positive breast cancer is associated with poor benefit of tamoxifen. Breast Cancer Res Treat 2019; 174: 121-127.

20. Mo Z, Liu M, Yang F, et al. GPR30 as an initiator of tamoxifen resistance in hormone-dependent breast cancer. Breast Cancer Res 2013; 15: R114. 
21. Eggemann H, Bernreiter A-L, Reinisch $M$, et al. Tamoxifen treatment for male breast cancer and risk of thromboembolism: prospective cohort analysis. Br J Cancer 2019; 120: 301-305.

22. Eggemann H, Brucker C, Schrauder M, et al. Survival benefit of tamoxifen in male breast cancer: prospective cohort analysis. $\mathrm{Br}$ J Cancer 2020; 123: 33-37.

23. Altman DG, Lausen B, Sauerbrei W, Schumacher M. Dangers of using "Optimal" Cutpoints in the Evaluation of Prognostic Factors. JNCI 1994; 86: 829-835.

24. Ignatov T, Eggemann H, Semczuk A, et al. Role of GPR30 in endometrial pathology after tamoxifen for breast cancer. Am J Obst Gynecol 2010; 203: 595.e9-595.e16.

25. Broselid S, Cheng B, Sjöström M, et al. G protein-coupled estrogen receptor is apoptotic and correlates with increased distant disease-free survival of estrogen receptor-positive breast cancer patients. Clinical Cancer Res 2013; 19: 1681-1692.

26. Friese K, Kost B, Vattai A, et al. The G protein-coupled estrogen receptor (GPER/GPR30) may serve as a prognostic marker in early-stage cervical cancer. J Cancer Res Clin Oncol 2018; 144: 13-19.

27. Schüler-Toprak S, Skrzypczak M, Ignatov T, et al. G protein-coupled estrogen receptor 1 (GPER-1) and agonist G-1 inhibit growth of ovarian cancer cells by activation of anti-tumoral transcriptome responses: impact of GPER-1 mRNA on survival. J Cancer Res Clin Oncol 2020; 146: 3175-3188.

28. François CM, Wargnier R, Petit F, et al. $17 \beta$-estradiol inhibits spreading of metastatic cells from granulosa cell tumors through a non-genomic mechanism involving GPER1. Carcinogenesis 2015; 36: 564573.

29. Filardo EJ, Graeber CT, Quinn JA, et al. Distribution of GPR30, a seven membrane-spanning estrogen receptor, in primary breast cancer and its association with clinicopathologic determinants of tumor progression. Clin Cancer Res 2006; 12: 6359-6366.

30. Ignatov T, Treeck O, Kalinski T, et al. GPER-1 expression is associated with a decreased response rate to primary tamoxifen therapy of breast cancer patients. Arch Gynecol Obst 2020; 301: 565-571.

31. Polley M-YC, Dignam JJ. Statistical considerations in the evaluation of continuous biomarkers. J Nucl Med 2021; 62: 605-611.

32. Westfall PH, Young SS. Resampling-based multiple testing: examples and methods for $p$-value. Adjustment, Wiley, New York, 1993.

33. Eggemann $H$, Ignatov $A$, Smith BJ, et al. Adjuvant therapy with tamoxifen compared to aromatase inhibitors for 257 male breast cancer patients. Breast Cancer Res Treat 2013; 137: 465-470.

34. Bradley KL, Tyldesley S, Speers CH, et al. Contemporary systemic therapy for male breast cancer. Clin Breast Cancer 2014; 14: 31-39.

35. Masci G, Caruso M, Caruso F, et al. Clinicopathological and immunohistochemical characteristics in male breast cancer: a retrospective case series. Oncologist 2015; 20: 586-592.

36. Sjöström M, Hartman L, Grabau D, et al. Lack of G protein-coupled estrogen receptor (GPER) in the plasma membrane is associated with excellent long-term prognosis in breast cancer. Breast Cancer Res Treat 2014; 145: 61-71.

37. Losurdo A, Rota S, Gullo G, et al. Controversies in clinicopathological characteristics and treatment strategies of male breast cancer: a review of the literature. Crit Rev Oncol/Hematol 2017; 113: 283-291.

38. Tutzauer J, Sjöström M, Bendahl P-O, et al. Plasma membrane expression of $\mathrm{G}$ protein-coupled estrogen receptor (GPER)/G protein-coupled receptor 30 (GPR30) is associated with worse outcome in metachronous contralateral breast cancer. PLoS One 2020; 15: e0231786.

39. Samartzis EP, Noske A, Meisel A, et al. The G protein-coupled estrogen receptor (GPER) is expressed in two different subcellular localizations reflecting distinct tumor properties in breast cancer. PLoS One 2014; 9: e83296-e83296.

\section{Address for correspondence}

\section{Norbert Nass}

Department of Pathology

Otto von Guericke University Magdeburg

44 Leipziger St.

D-39120 Magdeburg, Germany

Phone: +49-391-67 17863, +49 3405011118

e-mail: norbert.nass@med.ovgu.de, Norbert.nass@klinikum-dessau.de

Submitted: 23.09 .2021

Accepted: 23.09 .2021 